\title{
Effect of the Shear Reinforcement Type on the Punching Resistance of Concrete Slabs
}

\author{
Kálmán Koris, András Kozma, István Bódi \\ Department of Structural Engineering, Budapest University of Technology and Economics, Budapest, Hungary \\ Email: koris.kalman@epito.bme.hu
}

How to cite this paper: Koris, K., Kozma, A. and Bódi, I. (2018) Effect of the Shear Reinforcement Type on the Punching Resistance of Concrete Slabs. Open Journal of Civil Engineering, 8, 1-11.

https://doi.org/10.4236/ojce.2018.81001

Received: December 11, 2017

Accepted: March 4, 2018

Published: March 7, 2018

Copyright $\odot 2018$ by authors and Scientific Research Publishing Inc. This work is licensed under the Creative Commons Attribution International License (CC BY 4.0).

http://creativecommons.org/licenses/by/4.0/

(c) (i) Open Access

\begin{abstract}
Punching shear failure of flat concrete slabs is a complex phenomenon with brittle failure mode, meaning sudden structural failure and rapid decrease of load carrying capacity. Due to these reasons, the application of appropriate punching shear reinforcement in the slabs could be essential. To obtain the required structural strength and performance in slab-column junctions, the effect of the shear reinforcement type on the punching resistance must be known. For this purpose, numerous nonlinear finite element simulations were carried out to determine the behavior and punching shear strength of flat concrete slabs with different punching shear reinforcement types. The efficiency of different reinforcement types was also determined and compared. Accuracy of the numerical simulations was verified by experimental results. Based on the comparison of numerical results, the partial factor for the design formula used in Eurocode 2 was calculated and was found to be higher than the actual one.
\end{abstract}

\section{Keywords}

Finite Element Method, Punching, Shear, Reinforcement, Slabs

\section{Introduction}

Several methods exist for reinforcing concrete slab-column junctions against punching shear. The purpose of all types of shear reinforcement is to increase the shear capacity of concrete members and to add ductility to their post-peak load behavior [1]. Strength and ductility considerations are the most important issues in evaluating the effectiveness of the punching shear reinforcement in slabs, but economy and ease of installation can also have an effect on the choice of the reinforcement type. The most common and widely used solutions are reinforcing bars formed into stirrups, bent down flexural reinforcement or addi- 
tional transverse inclined bars, structural steel sections and headed shear studs. We could not find any comprehensive, comparative analysis of all the mentioned reinforcing systems together, therefore, we decided to analyze them using non-linear finite element modeling by the commercial finite element software ATENA 3D v5.1.1. The results of this analysis may be used to find the best reinforcing solution in terms of punching shear capacity and economy for flat concrete slabs. For the verification of the numerical model test setups of three experimental campaigns, all together 40 experiments were reproduced.

\section{Experimental Background}

In order to ensure that the numerical model represents the real experiments adequately, the results of three previous test series were used. The first set of experiments were performed under the guidance of Guadalini [2], the second one was made by J. Alam [3] and the third one by Lips [4]. The experimental program of Guadalini consisted of 11 square slabs. The specimens were supported on a steel plate and the load was applied in 8 points. J. Alam's experiments consisted of 15 square reinforced slabs. Each slab was subjected to concentrated loading at the geometric centre. Four steel blocks were used at each corner of the slab as support. Lips investigated sixteen square slab specimens with and without shear reinforcement. His principal aim was the analysis of flat slabs with large amounts of punching shear reinforcement.

\section{Introduction of the Numerical Model}

The finite element software ATENA 3D [5] was employed to study the performance and structural behavior of the different punching shear reinforcement solutions. The applied software offers a fracture-plastic constitutive model for concrete, which combines constitutive models for tensile (fracturing) and compressive (plastic) behavior [6]. In case of the analyzed experiments, the compressive strength of concrete was the only confirmed material parameter. The software includes a set of relations in order to provide the required input data for the constitutive law. These relations help estimating the cylinder compressive strength, tensile strength, initial elastic modulus and the fracture energy. In these relationships, only the cubic strength of concrete $f_{c u}$ (nominal strength) is necessary for the calculation of the remaining parameters. There are parameters that are specifically related to the Fracture-plastic model in ATENA software. They represent the following features: volume plastic factor $\beta$ describes volume dilation during non associated plastic deformations within the plastic range, shear factor coefficient defines a relationship between the normal and shear crack stiffness, compression softening parameter $w_{d}$ represents a deformation of compression zone after the complete stress fading. For these parameters, the values proposed by Červenka [6] were used.

A sensitivity analysis was carried out to assess the effects of the different parameters on the obtained results. The analysis showed that the most important 
concrete parameter is the cubic strength, as all other parameters are derived from this value. The error in this value may cause error in the value of punching strength and stiffness as well. Shear factor, tensile strength and the strength reduction factor due to cracks do not affect the outcome of the calculation significantly. The parameter describing the specific fracture energy does not affect the stiffness of the structure, but it has a great influence on the punching strength, and on the load level, where the first cracks develop. Therefore, the good estimation of this parameter is essential in order to obtain acceptable results. In the applied numerical model this parameter was finally estimated by ATENA's built-in formulation. For the modeling of reinforcing bars bilinear stress-strain law with hardening was used. In the present study, discrete reinforcement was applied in form of embedded truss elements. The bond-slip relationship defined by CEB-FIB Model Code 1990 was used. The load introduction and the supports were realized using steel plates. These steel plates remain in elastic state in all cases during the loading procedure, therefore, it was enough to use an elasticisotropic material model. For that, only two material parameters were necessary: the Young's modulus and the Poisson's ratio.

Before analyzing the behavior of different reinforcement types, the study of finite elements was carried out, which showed that hexahedron elements are capable of capturing the stiffness of the real experiments more accurately than tetrahedron elements. The application of second order shape functions instead of linear ones did not lead to more accurate results. A mesh study showed that applications of 5 finite elements through the thickness of the slab are enough to obtain acceptable results. Further refinement did not bring improvement, however, it increased the computational time drastically.

All analyzed specimens were doubly symmetrical flat concrete slabs loaded in the middle. This symmetry was utilized to reduce the model size: only the quarter of the structure was modeled (Figure 1). The effect of symmetry was modeled as restrains against horizontal translations perpendicular to the plane of the symmetry, while all other translations were kept unrestrained. The vertical supports were modeled as nonlinear springs that have extremely large stiffness in compression and zero stiffness in tension. This way, unrealistic tensile cracks in the support region could be avoided by the model [7].

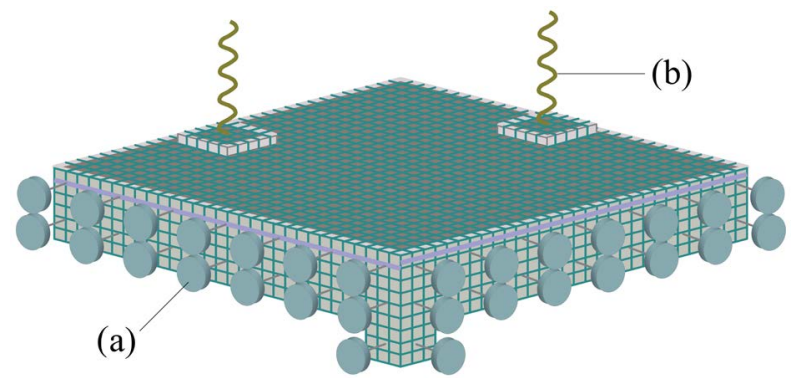

Figure 1. The applied numerical model: (a) restrains against horizontal translations, (b) springs for vertical displacements. 
During the analysis the load was applied to the column head as a prescribed displacement and the resistance was recorded as the reaction force at the loading point. For the solution the standard Newton-Raphson iterative technique was used with a tangent stiffness and admissible error of residual forces at $1 \%$.

The model verification consisted of on the one hand the comparison of cracking patterns of the numerical analysis and the real experiments, and on the other hand of the statistical analysis of the error terms. In the frame of the research of Lips [4] saw-cuts were made in order to analyze the cracks after failure. The photos of these saw-cuts were available, thus the numerically and experimentally obtained cracking patterns could be compared. This comparison can be seen in Figure 2(b). The numerically obtained crack patterns were put onto the original photos with $70 \%$ transparency. In the right part of the figures the blue line indicates the experimentally obtained, and the black lines show the numerically determined cracks. The color scale shows the rate of the principal fracturing strain.

Red color indicates the highly fractured areas. In the majority of the analyzed experiments, the shape and the size of the failure surfaces obtained by numerical simulations were in good agreement with the experimentally obtained ones.

For the statistical evaluation of the numerical model's accuracy, altogether 40 experiments were reproduced with the help of numerical simulation. For each specimen the model uncertainty parameter was determined as the ratio of the experimentally measured $\left(V_{\text {exp }}\right)$ and the numerically calculated $\left(V_{\text {num }}\right)$ punching shear capacities:

$$
\theta=V_{\text {exp }} / V_{\text {num }} .
$$

In our previous research [8] the uncertainty parameters belonging to the current Eurocode 2 formulation were determined on the same set of experiments. It was possible this way to directly compare the reliability of the numerical simulation and the design formula on punching shear resistance of the slab without shear reinforcement, using equation 6.2.a from EN 1992-1-1 (Eurocode 2) Standard [9]:

$$
V_{R d, c}=0.18 \cdot u_{1} \cdot d \cdot k \cdot\left(100 \cdot \rho \cdot f_{c}\right)^{1 / 3} \geq v_{\min } \cdot u_{1} \cdot d
$$

where $u_{1}$ is the basic control perimeter, $d$ is the effective depth of the slab, $k$ is the size effect factor, $\rho$ is the reinforcement ratio, $f_{c}$ is the characteristic cylinder strength of concrete and $V_{\min }$ is the lower limit of the specific punching shear strength. Statistical analyses were carried out on both sets of uncertainty parameters, and the corresponding safety factors were determined according to EN 1990-Annex $D$ [10] and JCSS 2001 [11]. The main parameters of the statistical analyses are summarized in Table 1 . The safety factor used in the current design formula is $\gamma_{c}=1.5$ [12]. However, the statistical analysis of the results showed that a higher value, 2.177 would be necessary for the required reliability level. The uncertainty in the results of the numerical analysis was significantly smaller 


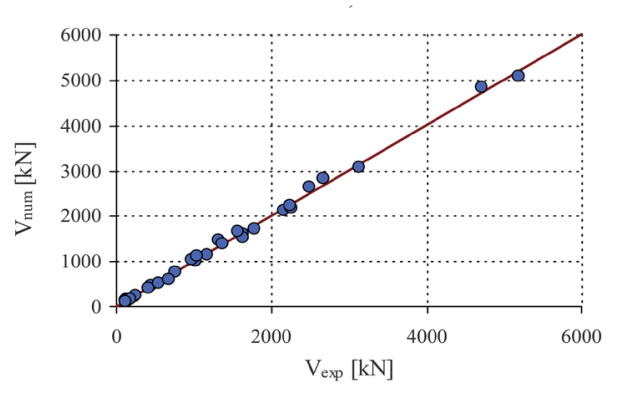

(a)

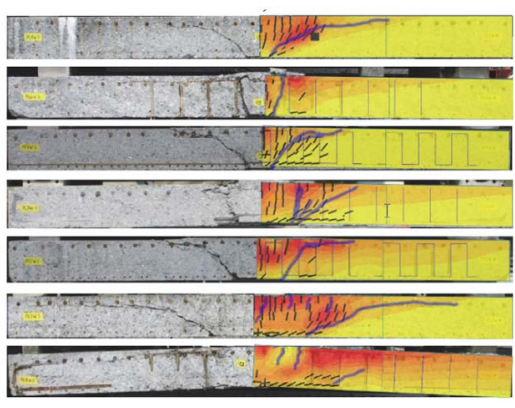

(b)

Figure 2. Comparison of numerical and experimental results: (a) Ultimate load, and (b) Cracking patterns. Photos from [13].

Table 1. The main statistical parameters of the model uncertainties.

\begin{tabular}{cccc}
\hline & & Numerical model & EN 1992 formulation \\
\hline Mean value & $\mu_{\theta}$ & 1.002 & -0.092 \\
Standard deviation & $\sigma_{\theta}$ & 0.065 & 0.034 \\
Coefficient of variation & $V_{\theta}$ & 0.065 & 0.193 \\
$\begin{array}{c}\text { Safety factor due to model } \\
\text { uncertainty }\end{array}$ & $\gamma_{R d^{*}}$ & 1.080 & 1.721 \\
$\begin{array}{c}\text { Safety factor due to material } \\
\text { uncertainties }\end{array}$ & $\gamma_{M}$ & 1.331 & 2.177 \\
\hline
\end{tabular}

than in the results of the analytical approach, because the analytical approach in Eurocode 2 overestimates the punching shear resistance in case of smaller column thicknesses and lower shear reinforcement quantities. Thus, the corresponding safety factor could be as low as 1.331 .

\section{Introduction of the Analyzed Reinforcement Systems}

With the help of the developed numerical model, the behaviors of different punching shear reinforcement systems were analyzed (Figure 3). A model without shear reinforcement was also built, in order to have a benchmark for the later comparison of the reinforcement systems. The geometric and material properties of the model can be found in Table 2 and Table 3.

Subsequently, 16 different models were built with different types and amounts of shear reinforcement. In all cases the material parameters, the geometrical properties of the slab and the layout of longitudinal reinforcement were kept constant. The models were created with the modification of the benchmark model by adding the shear reinforcement. The analyzed systems and their variable parameters are summarized in Table 4.

\section{Results of the Analyses}

In the followings the results of the numerical simulations of slabs with reinforcement types introduced above, are presented. All slabs $\left(V_{\text {num }, i}\right)$ were compared 
Table 2. Geometrical parameters of the numerical model.

\begin{tabular}{cccccc}
\hline Span & Thickness & Effective depth & Column size & Reinforcement & $\rho$ \\
\hline$[\mathrm{mm}]$ & {$[\mathrm{mm}]$} & {$[\mathrm{mm}]$} & {$[\mathrm{mm}]$} & {$[\mathrm{mm}]$} & $\varnothing \%]$ \\
\hline 3000 & 250 & 200 & 260 & $\varnothing 20 / 100$ & 1.57 \\
\hline
\end{tabular}

Table 3. Material parameters of the numerical model.

\begin{tabular}{ccccccc}
\hline $\begin{array}{c}\text { Cylinder } \\
\text { strength, } f_{c}\end{array}$ & $\begin{array}{c}\text { Cubic } \\
\text { strength, } f_{c u}\end{array}$ & $\begin{array}{c}\text { Tensile } \\
\text { strength, } f_{c t}\end{array}$ & $\begin{array}{c}\text { Young's } \\
\text { modulus, } E\end{array}$ & $\begin{array}{c}\text { Fracturing } \\
\text { energy, } G_{F}\end{array}$ & $\begin{array}{c}\text { Longitudinal } \\
\text { bars, } f_{y}\end{array}$ & $\begin{array}{c}\text { Shear reinforcement, } \\
f_{y w}\end{array}$ \\
\hline$[\mathrm{MPa}]$ & {$[\mathrm{MPa}]$} & {$[\mathrm{MPa}]$} & {$[\mathrm{MPa}]$} & {$[\mathrm{MN} / \mathrm{m}]$} & {$[\mathrm{MPa}]$} & {$[\mathrm{MPa}]$} \\
\hline 34.2 & 40.2 & 2.818 & 34103 & $7.095 \mathrm{E}-05$ & 554.0 & 592.0 \\
\hline
\end{tabular}

Table 4. Variable parameters of the numerical analyses.

\begin{tabular}{cccc}
\hline Shear reinforcement & Abbreviation & Number of models & Variable parameters \\
\hline- & SR0 & 1 & Diameter, spacing and number of the studs \\
Studs & ST & 4 & Diameter of the bars \\
Bent bars & BB & 3 & Spacing and number of stirrups, diameter of the longitudinal bars \\
Hidden beams & HB & 3 & Diameter of the cages, number of vertical branches, spacing \\
Cages of stirrups & CS & 3 & Height and cross-sectional area of the I sections \\
Shear heads & SH & 3 &
\end{tabular}

to the results of specimen SR-0 ( $\left.V_{\text {num,SR-0 }}\right)$, which does not contain shear reinforcement. For all specimens containing shear reinforcement an effectiveness was calculated:

$$
\text { Effectiveness }=\left(\mathrm{V}_{\text {num }, \mathrm{i}}-V_{\text {num }, S R-0}\right) / m_{w}
$$

where $m_{w}$ is the weight of the applied punching shear reinforcement.

This value shows the increment of the punching load due to a unit kilogram of shear reinforcement. The determined effectiveness values are presented in Table 5 .

The calculated cracking patterns in case of different punching shear reinforcement types are illustrated in Figure 4. According to the results of numerical analyses, an increase in the amount of shear studs causes a decrease in the inclination of the punching cone. This can be explained by the crack bridging ability of the studs. In case of specimens ST-3 and ST-4 less cracks can be observed. In accordance with the expectations, a larger amount of shear reinforcement can prevent crack opening more efficiently, however, increasing the amount of studs does not bring an increase in the punching resistance after a certain point.

In case of slabs with bent bars only minor differences were observed in the outcome of the analysis. The punching cone has the same shape in all cases, the cracking patterns are also very similar. The diameter of the bent bars has no effect on the failure mode, but it can increase the load bearing capacity of the slabs. 
Table 5. Calculated shear strength and effectiveness of different reinforcement solutions.

\begin{tabular}{lcccc}
\hline & Reinforcement weight & $V_{\text {num }}$ & $\begin{array}{c}\text { Increase in } \\
\text { shear strength }\end{array}$ & Effectiveness \\
\cline { 2 - 5 } Specimen & {$[\mathrm{kg}]$} & {$[\mathrm{kN}]$} & {$[\%]$} & {$[\mathrm{kN} / \mathrm{kg}]$} \\
\hline SR-0 & - & 1076 & - & - \\
ST-1 & 8.48 & 1216 & $13.0 \%$ & 16.5 \\
ST-2 & 16.63 & 1592 & $48.0 \%$ & 31.0 \\
ST-3 & 43.65 & 1908 & $77.3 \%$ & 19.1 \\
ST-4 & 25.33 & 1908 & $77.3 \%$ & 32.8 \\
BB-1 & 9.69 & 1940 & $80.3 \%$ & 89.2 \\
BB-2 & 16.91 & 1996 & $85.5 \%$ & 54.4 \\
BB-3 & 40.11 & 2120 & $97.0 \%$ & 26.0 \\
HB-1 & 21.90 & 1924 & $78.8 \%$ & 38.7 \\
HB-2 & 19.77 & 1904 & $77.0 \%$ & 41.9 \\
HB-3 & 42.85 & 1952 & $81.4 \%$ & 20.4 \\
CS-1 & 29.83 & 1912 & $77.7 \%$ & 28.0 \\
CS-2 & 44.75 & 1952 & $81.4 \%$ & 19.6 \\
CS-3 & 104.41 & 2004 & $86.2 \%$ & 8.9 \\
SH-1 & 40.82 & 1880 & $74.7 \%$ & 6.7 \\
SH-2 & 47.73 & 1812 & $68.4 \%$ & $77.7 \%$ \\
SH-3 & 16.17 & 1912 & & 19.7 \\
\hline & & & & 2.7 \\
\hline
\end{tabular}

In a lower load level, the behavior of the tested specimens was almost the same. The highest stresses in specimen BB-1 arise in the vicinity of the column, which is in accordance with the expectations. The inclined parts are almost perpendicular to the failure surface; that is the reason why bent bars can increase the punching capacity more efficiently than shear studs.

Cages of continuous stirrups can increase the punching strength significantly. This kind of reinforcement has a good crack bridging ability, only a few cracks are wider than $0.1 \mathrm{~mm}$ after failure. The distance between the vertical branches of the cages affected the size of the punching cone: a denser placement resulted in smaller inclination of the failure surface. This reinforcement system requires, however, a huge amount of steel bars, therefore, the calculated effectiveness is smaller than in the other cases.

Application of hidden beams can also improve the load carrying capacity and the deformation capability significantly. The distance between the applied stirrups has only a minor effect on the outcome. This kind of reinforcement has smaller crack bridging ability than the cages of continuous stirrups. The effectiveness of this reinforcement system is better than the effectiveness of shear studs or continuous stirrups. 


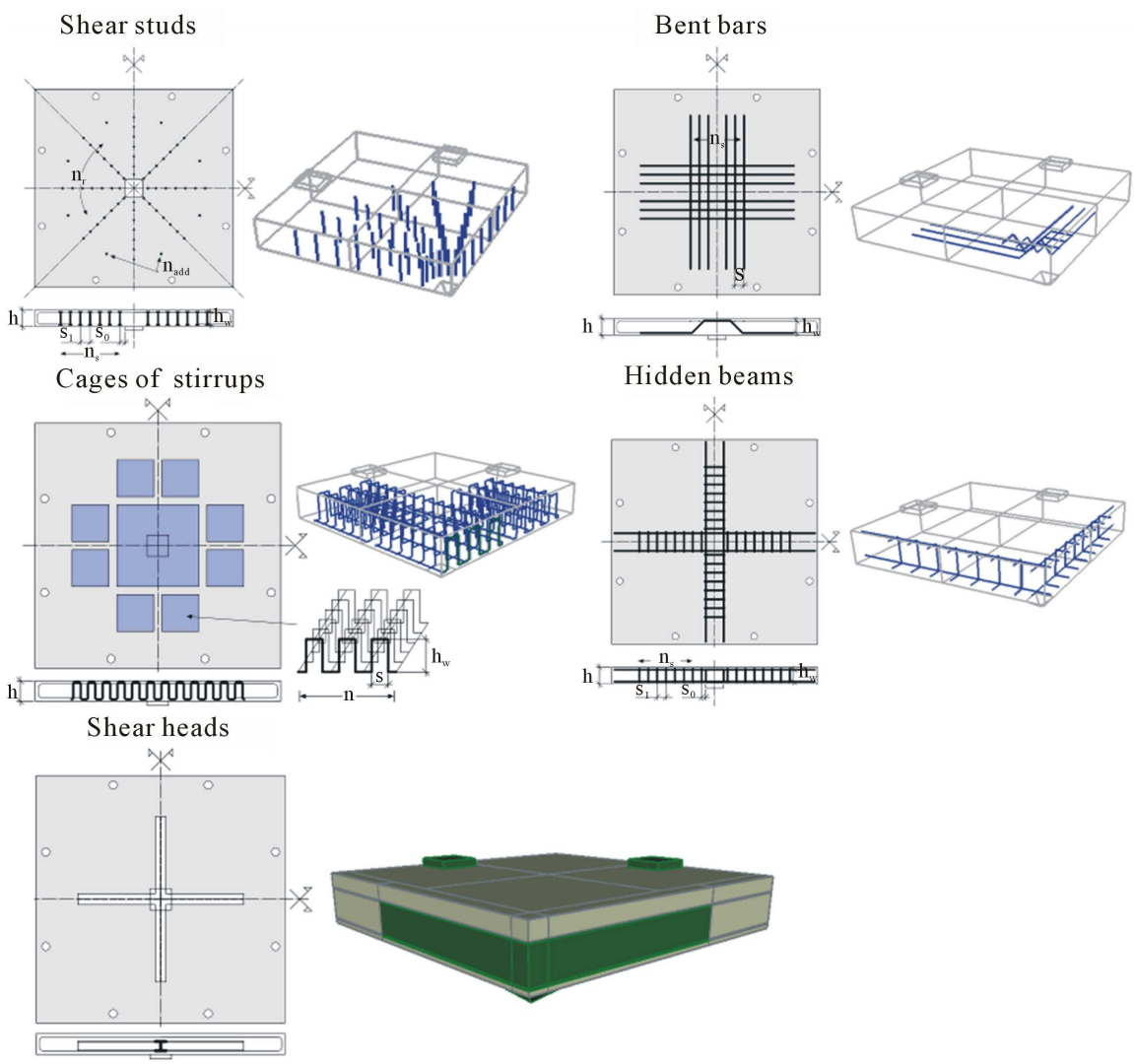

Figure 3. The analysed punching shear reinforcement systems and their corresponding numerical models.

Structural steel sections change the behavior of the slab. The failure does not happen along a conical surface. In all cases the stresses in the steel sections reached the yield strength of the material. In case of slabs SH-1 and SH-3 the yield strength was utilized along almost the whole section, while in case of specimen $\mathrm{SH}-2$ the stresses reached the yield strength only in the vicinity of the column. That is the reason why specimen SH-2 had the smallest value for punching strength and the smallest deformation capability, while this slab included the largest amount of steel. The other slabs had a quite similar effect on the load level that might cause failure, but the wider flanges of specimen $\mathrm{SH}-1$ increased the deformation capability of the slab more efficiently. The calculated effectiveness of slabs SH-1 and SH-2 is below the average of the analyzed slabs, but the performance of slab SH-3 is one of the most efficient ones.

In Figure 5, the load-deflection diagrams of the strongest slabs among each type of reinforcement system are presented and compared to each other.

The initial stiffness of almost all slabs is equal to the stiffness of the slab without shear reinforcement. This can be explained by the fact that the software does not take the shear stiffness of the steel bars into account. The only exception is specimen SH-3 where the shear reinforcement is provided by structural steel sections which were modeled by $3 \mathrm{D}$ brick elements. After the cracking load is 

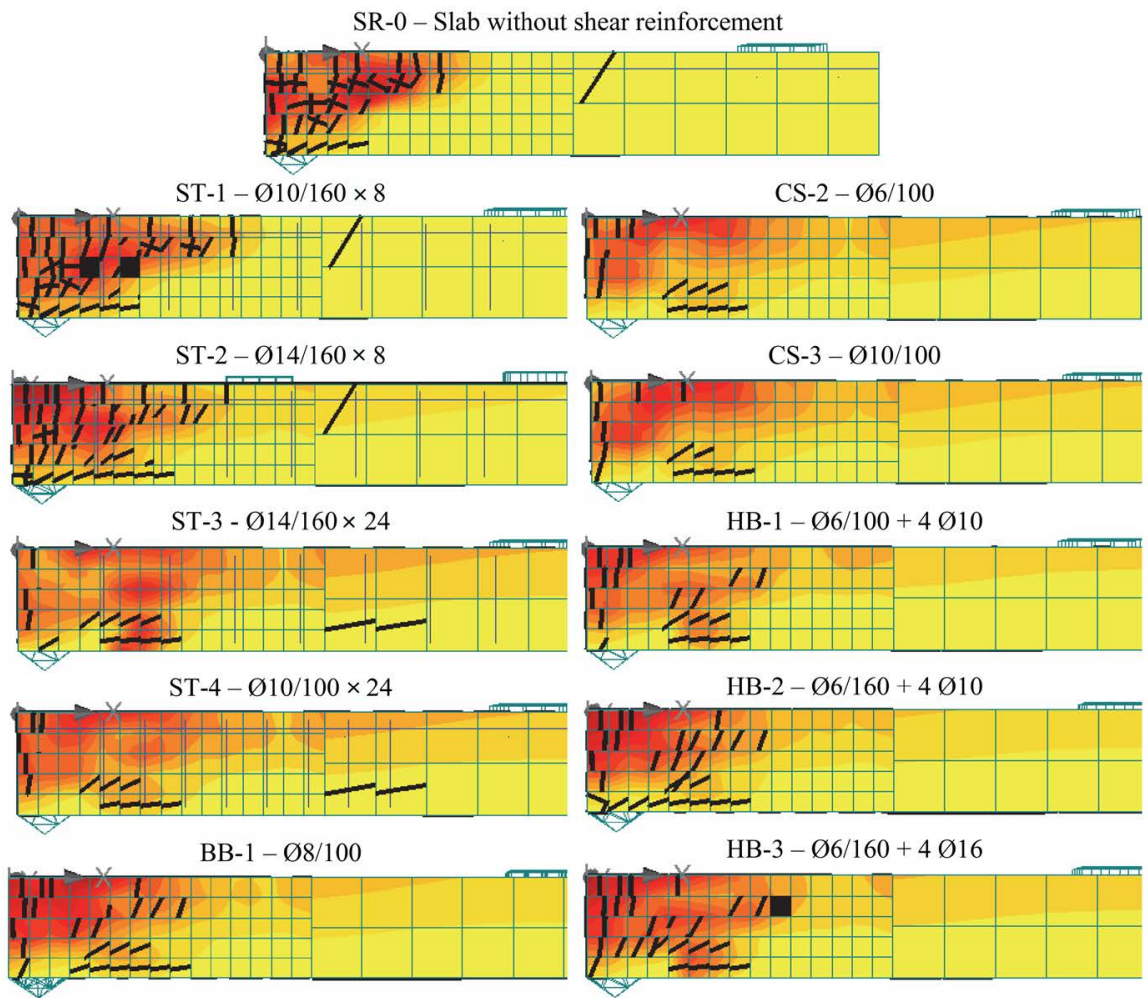

BB-2 - Ø10/100

SH-1 - IPB 100; A=26.0 $\mathrm{cm}^{2}$
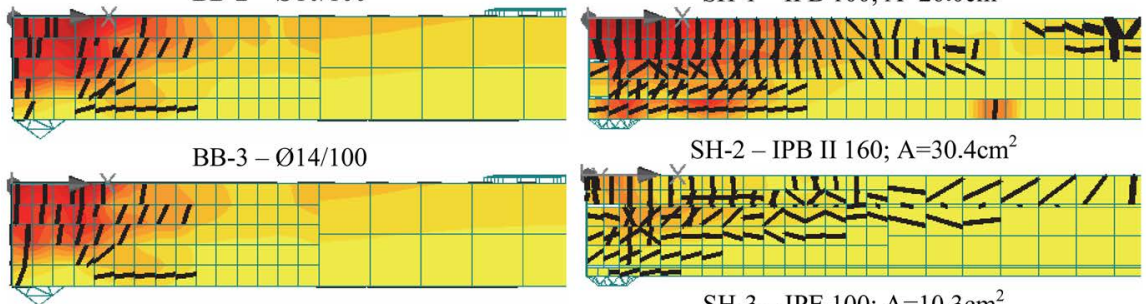

$\mathrm{SH}-2$ - IPB II 160; $\mathrm{A}=30.4 \mathrm{~cm}^{2}$

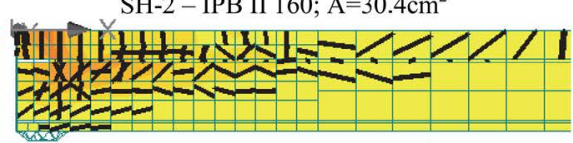

SH-3 - IPE 100; $A=10.3 \mathrm{~cm}^{2}$
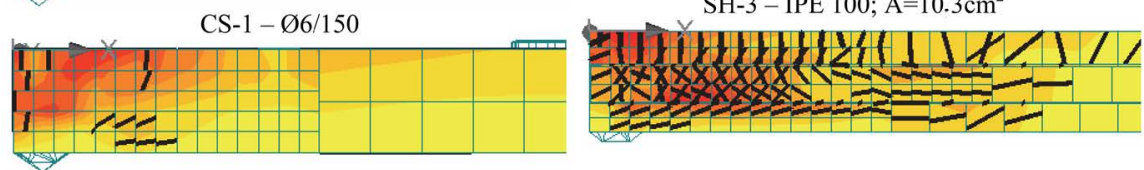

Figure 4. Cracking patterns in case of different reinforcement systems.

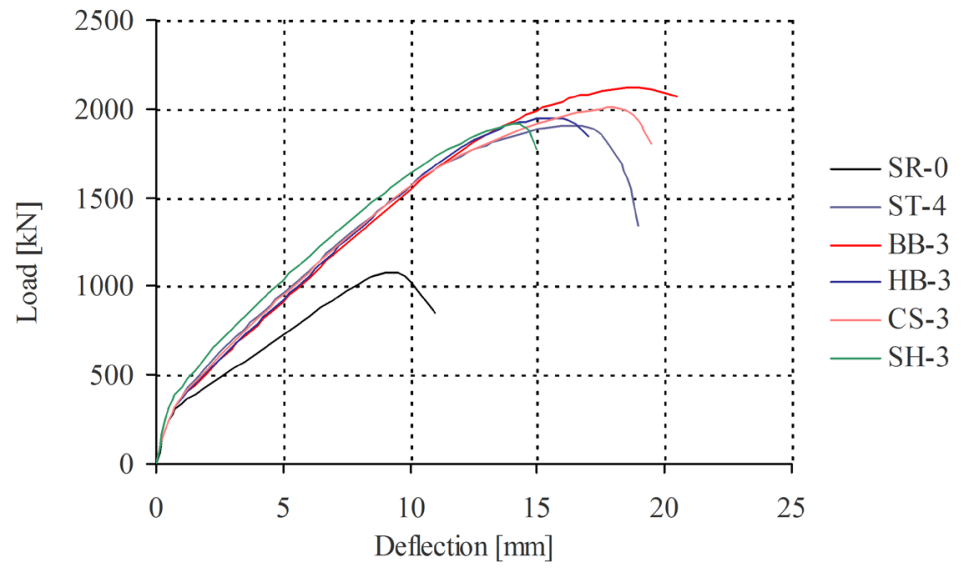

Figure 5. Load-deflection diagrams of slabs with different reinforcement systems. 
reached, the stiffness of the analyzed slabs deviate from each other but not significantly. However, all slabs act much stiffer than the one without shear reinforcement. The highest punching shear capacity and effectiveness is provided by the bent bars, since these bars are perpendicular to the plane of the cracks, and they are efficiently anchored in the concrete. The second largest punching shear capacity is provided by the cages of stirrups, thanks to the efficient anchorage provided by the spatial steel bar arrangement. Despite its good general judgment (because of its effectiveness and easy mounting), shear studs provide the least punching shear resistance among the tested configurations, which is mainly caused by their small length and limited anchorage capabilities. The smallest deformation capability belongs to the slab with steel sections, while the largest deflections belong to slabs BB-3 and CS-3. Slab BB-3 contains only $40 \%$ of the amount of reinforcement applied in slab CS-3. Due to this fact bent bars are the most efficient type of shear reinforcement in the aspect of load carrying capacity and deformation capability as well.

\section{Conclusion}

It was demonstrated that the calibrated numerical model could reproduce real experiments with a high accuracy. The cracking patterns and ultimate loads obtained by numerical simulations were in good agreement with experimental results. To capture the real behavior of the structure, the most important concrete parameter is the cubic strength, as all other parameters are derived from this value. The error in this value causes error not just in the punching strength, but in the stiffness as well. Comparing the performance of different punching shear reinforcement types, the application of bent bars is the most effective way to increase the punching strength and the deformation capability of the slabs. The placement of such bars could be, however, difficult in heavily reinforced column-slab junctions. The arrangement of the bars, stirrups and studs play a vital role in the effectiveness of the applied reinforcement, while their size has smaller effect on the punching strength. Hidden beams can be used as punching reinforcement more efficiently than shear studs. The effectiveness of shear studs is not the best, but they can produce acceptable strength increase with high deformation capability and their application usually does not cause construction problems. Cages of continuous stirrups are the least effective punching shear reinforcement system. The applicability of such cages in heavily reinforced connections is also questionable. Structural steel sections can also be used efficiently. The main disadvantage is the difficulty in placing the shear head between the longitudinal bars of the slab and the column.

\section{References}

[1] Polak, M.A., El-Salakawy, E. and Hammill, N.L. (2005) Shear Reinforcement for Concrete Flat Slabs, ACI (American Concrete Institute), SP-232, 75-90.

[2] Guadalini, S. and Muttoni, A. (2009) Punching Tests of Slabs with Low Reinforce- 
ment Ratios. ACI Structural Journal, 2009, 87-95.

[3] Alam, J., Khan, M.A. and Salek, M.S. (2009) An Experimental Study on Punching Shear Behavior of Concrete Slabs. Advances in Structural Engineering, 12, 257-265. https://doi.org/10.1260/136943309788251650

[4] Lips, S. and Muttoni, A. (2010) Experimental Investigation of Reinforced Concrete Slabs with Punching Shear Reinforcement. 8th Fib International PhD Symposium in Civil Engineering, Kgs. Lyngby, Denmark, 75-80.

[5] Červenka, V. and Červenka, J. (2014) User's Manual for ATENA 3D, ATENA Program Documentation, Part 2-2. Červenka Consulting s.r.o., Prague, Czech Republic.

[6] Červenka, V., Libor, J. and Červenka, J. (2014) ATENA Program Documentation: Part 1 Theory. Červenka Consulting s.r.o., Prague, Czech Republic.

[7] Kadlec, L. and Červenka, V. (2015) Uncertainty of Numerical Models for Punching Resistance of RC Slabs. Fib Symposium Proceedings: Concrete, Innovation and Design, Copenhagen, Denmark, 1-13.

[8] Kozma, A., Bódi, I. and Koris, K. (2016) Partial Factor Assessment for the Punching Shear Resistance of Flat Concrete Slabs. Proceedings of the 11 th Fib International PhD Symposium in Civil Engineering, Tokyo, Japan, 657-662.

[9] Eurocode (2010) EN 1992-1-1:2010: Eurocode 2: Design of Concrete Structures, Part 1-1: General Rules and Rules for Buildings. Hungarian Standards Institution, Budapest, Hungary.

[10] Eurocode (2011) EN 1990:2011: Basis of Structural Design, Annex D, Chapter 8. Hungarian Standards Institution, Budapest, Hungary.

[11] Joint Committee on Structural Safety (2001) JCSS Probabilistic Model Code Part 3: Resistance Models.

[12] Soukhov, D. and Jungwirth, F. (1997) Conformity and Safety of Concrete According to prEN 206 and Eurocodes. Leipzig Annual Civil Engineering Report, No. 2, Leipzig, Germany.

[13] Lips, S. (2012) Punching of Flat Slabs with Large Amounts of Shear Reinforcement. PhD Dissertation, École Polytechnique Fédérale De Lausanne, Lausanne. 